\title{
DAS DEIR EL-MEDINE-OSTRAKON DER LEHRE FÜR MERIKARE
}

Summary: The ostracon Deir el-Medineh 1476, originally published by G. Posener, could be identified as a manuscript of the classical Egyptian teaching for king Merikare. A close examination of the original has resulted in a number of new and improved readings. The results are presented here together with the first published photograph of the ostracon.

Key words: Egyptian, Wisdom Text, King Merikare, Ostracon.

Ernö Gaál hat sich immer für die Literatur des Mittleren Reiches interessiert und dabei unter anderem ein Ostrakon der Lehre eines Mannes für seinen Sohn veröffentlicht, das für die Textkonstituierung von einiger Bedeutung war. ${ }^{1}$ Insofern erscheint es als angemessener Tribut zu seinem Andenken, wenn hier ebenfalls ein Ostrakon mit einem literarischen Text des Mittleren Reiches vorgelegt wird.

Das betreffende Stück ist kein Unbekannter, war es doch bereits von George Posener im Rahmen der Publikation der literarischen Ostraka aus den französischen Grabungen in Deir el-Medine als Nummer 1476 vorgelegt worden. ${ }^{2}$ Jedoch blieb die betreffende Publikation ohne Abbildung des hieratischen Originaltextes, da es Posener darauf ankam, in dem betreffenden Faszikel alle identifizierbaren Fragmente der Lehre des Königs Amenemhet und der Berufssatire vorzulegen, ${ }^{3}$ und er deshalb oft auf eine Beigabe des hieratischen Textes verzichtet hat. Relevant ist beim hier zu besprechenden Stück vor allem die zweite Seite, die von Posener nur als nicht identifizierter Text eingestuft worden war.

' GAÁl, E.: Ein neues Ostrakon zur „Lehre eines Mannes für seinen Sohn“. MDAIK 40 (1984) 13-25, Taf. 1-5.

${ }^{2}$ POSENER, G.: Catalogue des ostraca hiératiques littéraires de Deir el Médineh. Tome III. Kairo 1977, 48, Taf. 32.

${ }^{3}$ Vgl. POSENER (Anm. 2) Vf. 
Ich konnte dieses Fragment bereits anhand der publizierten Umschrift als Kopie der Lehre für Merikare identifizieren. ${ }^{4}$ Die Gelegenheit zu einer Inspektion des Originals ergab sich im September 2005 und hat in einem überraschend großen Aus$\mathrm{maß}$ weitere Lesungen erlaubt, so $\mathrm{da}$ es sinnvoll scheint, diese Seite des Ostrakons mit bildlicher Dokumentation neu vorzulegen. ${ }^{5}$ Selbstverständlich wird die Entzifferung dadurch erheblich erleichtert, daß durch die bekannten Parallelen ${ }^{6}$ bereits Vorgaben prinzipiell zu erwartender Zeichen gesetzt werden, und dies dürfte die Divergenzen zu Poseners Pionierarbeit weitgehend erklären.

Z. 1: Es sind sichere Spuren eines zweiten $k$ vorhanden. Die sonstigen Reste sind allerdings so spärlich und schwer auszumachen, daß ich auf eine Umschrift verzichtet habe. Damit ist nicht endgültig abzusichern, welchen der vier verschiedenen Suffixe $=k$ in der Parallele $\mathrm{E} 80$ sie genau entsprechen.

Z. 2: Gegen Poseners Lesung

b ist hç klar lesbar; außerdem deutliche Spuren von $t$ ' $-m h w$ identifizierbar. Die Lesung des am Zeilenende nach der Abplatzung noch erhaltenen Zeichens ist allerdings eine Crux, was um so bedauerlicher ist, als dies potentiell die einzige Stelle im Ostrakon ist, die substantiell weiterhelfen könnte, da die geographische Passage an dieser Stelle sich nicht eben durch Klarheit auszeichnet. ${ }^{7}$

Paläographisch wäre es denkbar, die erkennbaren Striche als rechten Teil eines 耏 $\mathrm{zu}$ verstehen, allerdings sind keine Spuren der restlichen Bestandteile des Zeichens auszumachen, zudem wäre diese Lesung angesichts der Raumverhältnisse nur akzeptabel, falls der Schreiber einen Teil der Zeile unbeschrieben gelassen hat.

Z. 3: Am Zeilenanfang sind die Spuren im Lichte der Parallelen sicher als $s$ zu deuten. Statt Poseners ist in Übereinstimmung mit den Parallelen imn.tt „Westen" erkennbar.

Z. 4: Die von mir schon ursprünglich vermutete Lesung $s$ statt Poseners $\|^{8}$ hat sich nicht nur bestätigt, sondern die nachfolgenden Spuren sind auch als Reste eines $n$ über einem nicht erhaltenen Zeichen auszumachen, so daß sich insgesamt das Suffix $s n$ ergibt.

${ }^{4}$ QUACK, J. F.: Zwei Ostraka-Identifizierungen. GM 115 (1990) 83-84; DERS.: Studien zur Lehre für Merikare [GOF IV/23]. Wiesbaden 1992.

${ }^{5}$ Für die Erlaubnis zur Veröffentlichung danke ich Laure Pantalacci, der Direktorin des IFAO Kairo, für die Unterstützung bei der Durchführung der Kollation Vanessa Ritter.

${ }^{6}$ Für eine Synopse s. QUACK: Merikare (Anm. 4) $180 \mathrm{f}$.

${ }^{7}$ Vgl. QUACK: Merikare (Anm. 4) 49f.

${ }^{8}$ QUACK: GM 115 (Anm. 4) 83. 

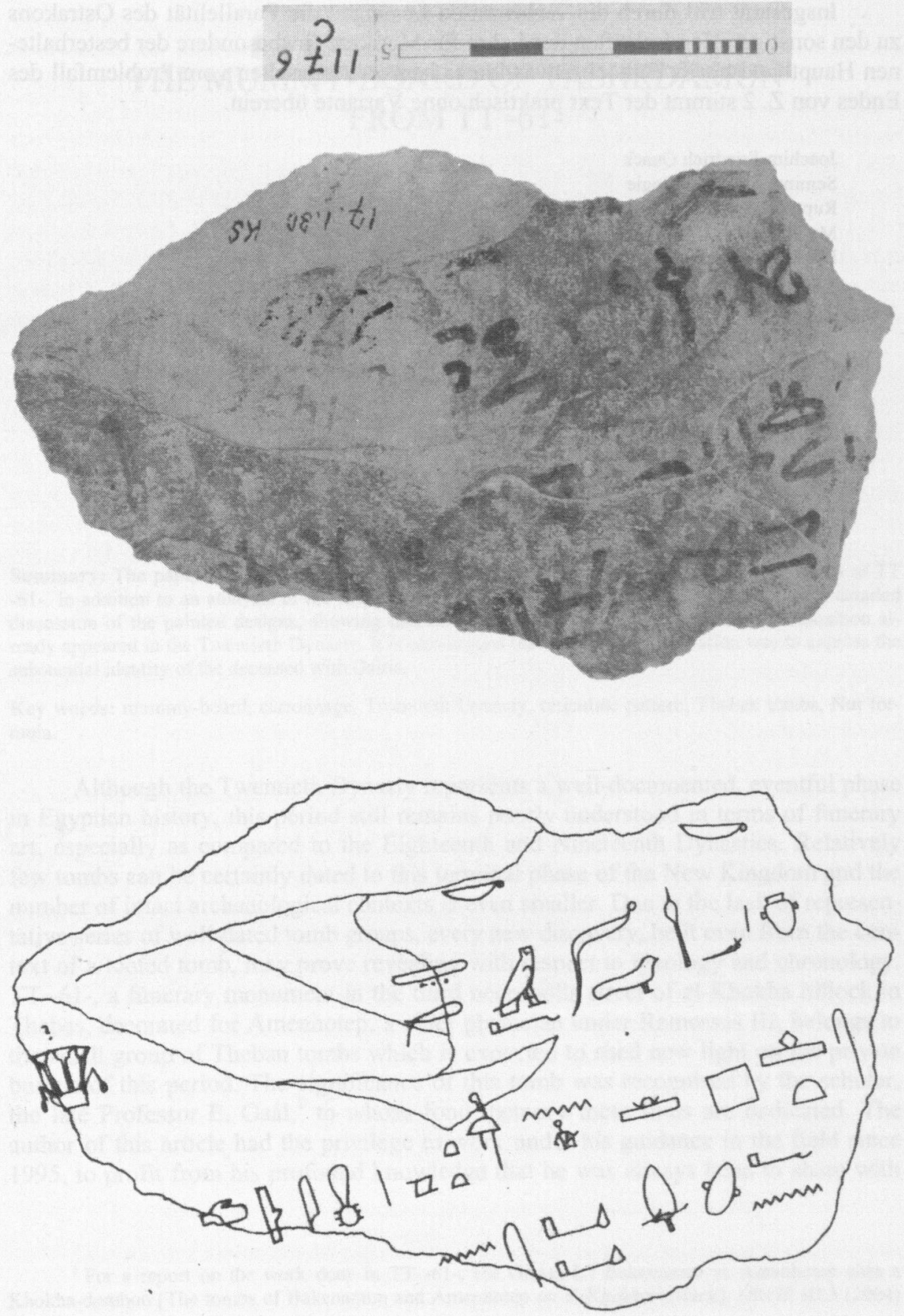
Insgesamt tritt durch die verbesserten Lesungen die Parallelität des Ostrakons zu den sonstigen Handschriften der Lehre für Merikare (insbesondere der besterhaltenen Haupthandschrift E) noch etwas klarer hervor. Abgesehen vom Problemfall des Endes von Z. 2 stimmt der Text praktisch ohne Variante überein.

Joachim-Friedrich Quack

Seminar für Ägyptologie

Ruprecht-Karls-Universität Heidelberg

Marstallhof 4

D-69117 Heidelberg 